\title{
Reducing energy consumption and increasing filter life in HVAC systems using an aspiration efficiency reducer: Long-term performance assessment at full-scale
}

David T Morgan ${ }^{\mathrm{a}}$, Terence Daly ${ }^{\mathrm{a}}$, John Gallagher ${ }^{\mathrm{a}, \mathrm{b}}$, Aonghus McNabola ${ }^{\mathrm{a}, *}$

${ }^{a}$ Dept of Civil, Structural \& Environmental Engineering, Trinity College Dublin, Ireland

${ }^{\mathrm{b}}$ School of Environment, Natural Resources \& Geography, Bangor University, United Kingdom

* Corresponding Author. Tel: (+353) 1896 3837, Email address: amcnabol@tcd.ie

\begin{abstract}
The concept of using an aspiration efficiency reducer (AER) in building heating ventilation and air conditioning (HVAC) systems to control particulate air pollution concentrations was previously demonstrated using a 1:4 scale experimental device. The AER acted as a passive form of air pollution control and reduced the particulate loading rate on filters in HVAC systems, thus reducing fan energy consumption. This paper discusses the design considerations that were accounted for in developing a full-scale AER device during a long-term performance assessment. A field assessment of a new full-scale AER device was performed at an urban commercial building in Dublin, Ireland. The results from two air handling units (AHUs), one Control-AHU and one AERAHU (with an attached AER device), allowed for a comparison of energy consumption and filter lifespans. Particulate matter (PM) and energy consumption in both AHUs were monitored over time for each AER design. The full-scale AER device reduced PM concentration entering the HVAC system by $34 \%$ over the operational life cycle of a filter, reducing energy consumption by up to $14 \%$. Alternatively the AER could be used to extend the lifespan of a filter by $75 \%$. The size distribution of PM deposited on the AER and Control filters established that the device was more effective for coarser particles. Energy and filter savings can be achieved using this passive
\end{abstract}


technique, which can translate to environmental, resource and economic savings in the building HVAC sector.

Keywords: heating, ventilation and air conditioning; energy consumption; filter life; aspiration efficiency; particulate matter; pressure drop.

\section{Introduction}

Air pollution in the urban atmosphere continues to receive a great deal of research focus in order to reduce its impact on human health, the environment and climate change [1]. Numerous sectors of society contribute to air pollution emissions. The buildings sector contributes to air pollution emissions in a number of ways including in the process of controlling air pollution for indoor environments [2].

The control of particulate air pollution in commercial and industrial buildings is a function that is typically carried out by heating ventilation and air conditioning (HVAC) systems [3]. The removal of particulate matter (PM) improves the health of the building occupants and also protects the components of the HVAC system itself $[4,5]$. This control of air pollution is normally carried out using air filtration. The use of filters to control indoor air quality can provide satisfactory pollution control performance but at the cost of additional energy, $\mathrm{CO}_{2}$ emission, natural resources and labour $[6,7]$.

The presence of a filter in the HVAC system increases the pressure drop across ventilation fans and increases energy consumption and $\mathrm{CO}_{2}$ emissions due to the resistance of the filters to air flow. This pressure drop also increases over time from its initial value when the filter is clean to a final 
pressure drop when the filter is saturated with trapped particles. Reducing this energy consumption is a significant problem and a major environmental concern for the HVAC industry [8].

Energy consumption in HVAC systems represents a very large proportion of energy consumption globally [9]. According to the EC's Joint Research Centre (2009), HVAC systems in the EU were estimated to account for 313 TWh of electricity or approximately $11 \%$ of all electricity consumed in 2007 [10]. In the US, HVAC systems are reported to account for 50\% of building energy requirements and $20 \%$ of total consumption [2]. According to several studies, consumption varies significantly ranging from between $20 \%$ and $70 \%$ of final building energy use $[2,8,11]$. The electricity demand of HVAC systems comprises energy consumed in heating, cooling, conditioning and exchanging air. Energy associated with air exchange is consumed by ventilation fans. The magnitude of this consumption in an individual building depends to a large extent on the pressure drop which a fan must overcome to achieve the desired air flow rates [7]. As such ensuring satisfactory levels of indoor air quality in buildings and human health protection comes at a significant cost to the environment as a whole in terms of climate change.

Opportunities to improve the energy efficiency of HVAC systems may help reduce consumption in buildings [8]. However, this requires balancing a complex relationship between climate conditions, building characteristics and the specific HVAC system [12, 13]. In particular, thermal comfort in buildings requires significant amounts of electricity, therefore reducing energy consumption without sacrificing comfort poses a clear challenge [14]. A study by Cho et al. [11] explains that the variety of HVAC systems presents the greatest challenge for providing a comprehensive framework for energy efficiency. A passive method of controlling the 
concentration of particulate pollution entering a HVAC system can provide a solution for improving energy efficiency over a systems operational lifespan [15].

This paper presents a new passive approach to the control of indoor air pollution in building HVAC systems with a view to improving the aforementioned energy consumption and environmental concerns. Based on the short-term test results of a previous 1:4 scale model [15], a long term performance assessment full-scale is examined here. This device uses the concept of Aspiration Efficiency, a phenomenon which affects the transport of particles in a fluid flow passing through an orifice. The proposed system facilitates a reduction in the loading rate of PM on existing filters over their lifetime, hence reducing the value of the final pressure drop and reducing energy consumption as a result. The following sections contain a description of a programme of full-scale long-term assessment of this concept at a commercial building in Dublin city centre, Ireland. The concept, design, modelling, installation and field assessment of the device are also described.

\section{Aspiration efficiency}

Aspiration Efficiency (AE), may be defined as the ratio of PM concentration passing through any orifice, $\mathrm{C}$, to that in the undisturbed ambient air concentration, $\mathrm{C}_{0}$, as shown in Equation 1 [16].

$$
\mathrm{AE}=\mathrm{C} / \mathrm{C}_{0} \times 100 \%
$$

A related concept, sampling efficiency (SE), is the efficiency at which particles are transported to the collection media (i.e. the filter). The AE and SE of a system are not necessarily equal as aspirated particles may be deposited on to the walls of the system (transmission losses) before reaching the filter. This concept has received significant attention in scientific literature over the 
past number of years and is an area of particle physics used in the development of PM measurement devices where an $\mathrm{AE}$ of $100 \%$ is most desirable [17]. However due to the many factors which influence the AE of a sampling device, $100 \%$ efficiency is not always achievable and hence in certain circumstances samplers may under- or over-sample the concentration of PM in the ambient environment, resulting in measurement errors $[18,19]$.

The factors which determine the AE of an orifice include: the orifice geometry, ambient wind speed and direction, PM characteristics (size, shape and concentration), and electrostatic effects. AE increases with increasing sampling/ventilation flow rate through the orifice. Where the wind direction is opposite to the direction of flow through the orifice, $\mathrm{AE}$ is reduced. Where the wind direction is opposite to the direction of flow through the orifice and wind speed is increasing $\mathrm{AE}$ is also reduced [20]. This effect is more pronounced for larger particle sizes. Values of AE vary widely in the literature: $20 \%$ to $160 \%$ for thin walled air pollution samplers; from $10 \%$ to over $200 \%$ for the human mouth; and from 10 to $95 \%$ at the inlet of building ventilation systems [15, 19-21]. Thus, sampler inlet design coupled with environmental conditions can result in significant differences between the PM concentrations of sampled and ambient air.

It was proposed by McNabola et al. [15] that the concept of $\mathrm{AE}$ could be used in reverse as a mechanism to control air pollution. By developing an air intake device specifically designed to be a very poor 'sampler' in terms of its AE, the device may act as a control system. This was subsequently proven and is described in detail in McNabola et al. [15]. This Aspiration Efficiency Reducer (AER) was found to prevent $54 \%$ of ambient $\mathrm{PM}_{2.5}$ on average from entering the inlet of a HVAC system at a commercial office building in Ireland, over a five-month period using a 1:4 
scale rotating device (see Figure 1). This prototype system achieved these reductions in $\mathrm{PM}_{2.5}$ concentration entering the HVAC inlet through the design of a new intake housing (the AER).
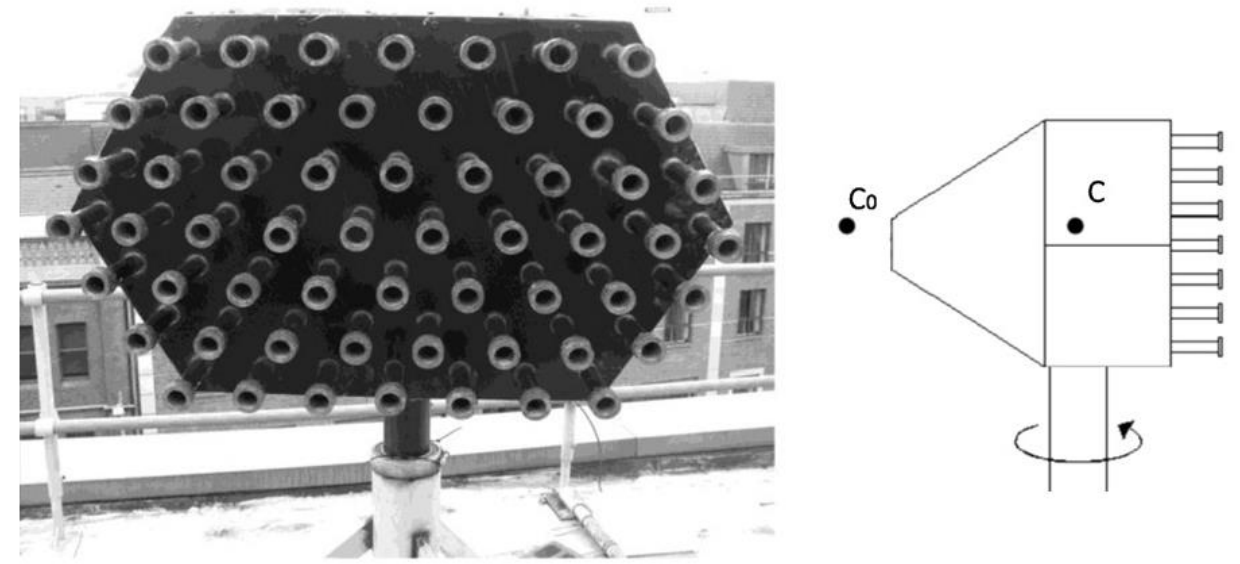

Figure 1. Original 1:4 scale prototype AER device on a rotating frame [15].

In tandem with existing filters, it was proposed that the AER device could act as a form of 'prefilter' to reduce the particle loading rate on existing filters, saving energy or extending filter life as a result. Preliminary estimates indicated that this reduction in loading rate could equate to a reduction in energy consumption of $15-20 \%$ at full scale. This was the case as the reduced loading rate was shown to have the potential to reduce the average pressure drop across a filter over a typical 6-month replacement cycle [4]. However a number of assumptions were inherent in scaling up the original prototype to a full scale air handling unit, and thus these energy savings estimates require real-world validation.

This paper reports on the next-generation design of an AER device to control indoor particulate air pollution in buildings. The design aims to reduce energy consumption in building HVAC systems and prolong the life of existing filters. A full-scale static AER device was designed and investigated in an extensive long term field campaign at a commercial building in Dublin, Ireland. This monitoring campaign aimed to quantify the energy savings and pollution control achievable using 
the AER concept, estimated in previous investigations. In addition, the ability of the AER to extend the life of filters was examined and the economic viability of the system was also quantified.

\section{Methodology}

\subsection{Design of static full-scale AER device}

Full-scale testing was conducted on two 860 x 600 mm, near-identical, air handling units (AHUs), each with a ventilation rate of $3,400 \mathrm{~m}^{3} / \mathrm{hr}$. Ventilation was achieved using variable speed drive fans to maintain a constant flow rate. The first AHU (the Control-AHU) helped establish a baseline for pollution control and energy consumption at the test location. The second AHU (the AERAHU) was fitted with the full scale AER attachment on its inlet. The two AHUs were located sideby-side on the roof of a three-storey commercial building located in Dublin City Centre (Figure 2), adjacent to congested roadways and subject to relatively high PM concentrations by Irish standards.
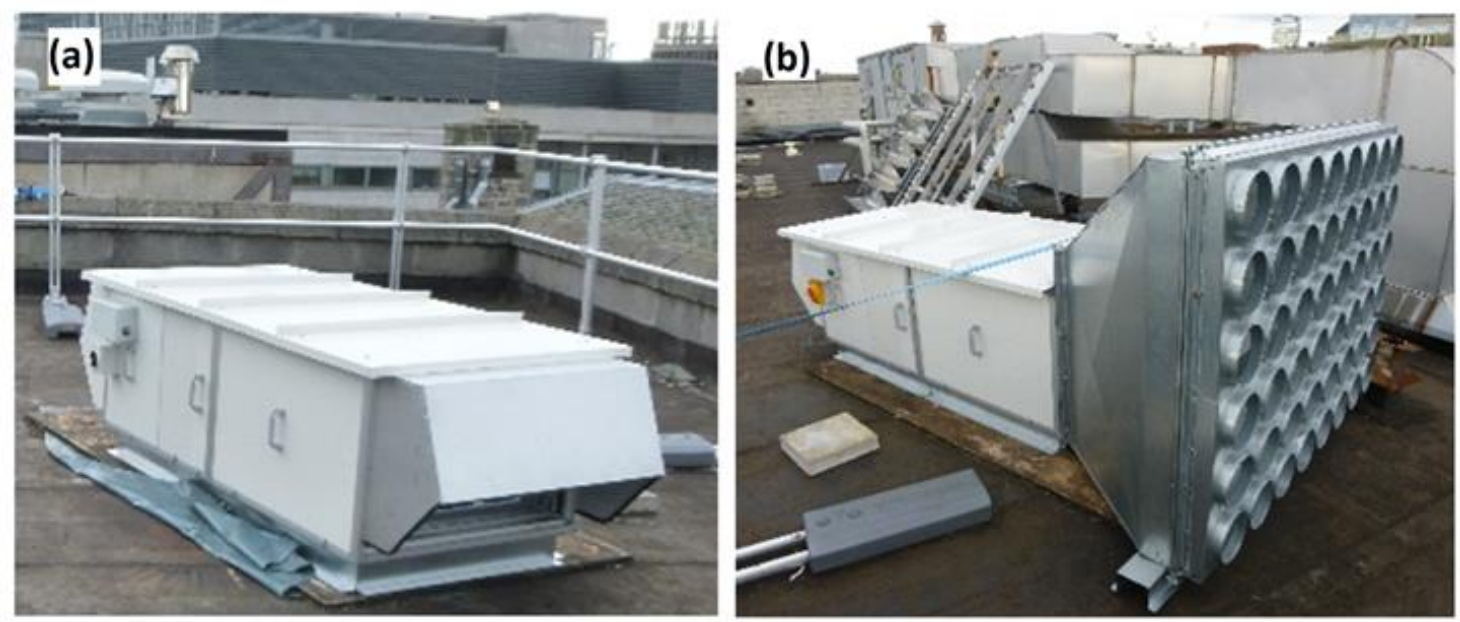

Figure 2. The Control-AHU and AER-AHU located on building rooftop in Dublin city centre. 
The original 1:4 scale AER prototype developed by McNabola et al. [15] was designed on the basis of three design principles as previous experiments had demonstrated they resulted in reduction in the AE of various orifices:

- Inlet is oriented opposite in direction to the ambient wind

- Ventilation velocity at the inlet is low $(<1 \mathrm{~m} / \mathrm{s})$

- Stokes number at the inlet is high

However at full-scale conditions meeting all of these design criteria is challenging due to practicalities relating to the available space, weight and cost of the device. For example reducing the inlet velocity and stokes number while not interfering with the ventilation flow rate, results in an inevitable increase in the cross-sectional area of the inlet. These increases in area to maintain a low inlet velocity become impractically large with increasing flow rate or decreasing velocity. As such a balance between performance and practicality is required at full-scale.

Due to the required size of the full-scale AER-AHU to maintain a low velocity at the intake, its ability to rotate and to be opposite in direction to ambient wind at all times was not feasible (due to weight and cost). The AER-AHU was instead fixed in position to have its intake oriented opposite to the most frequent prevailing wind direction. However, the full-scale design did meet with the other principles outlined. The number and diameter of the inlets in the AER-AHU were designed to maintain a low inlet velocity. In addition, as high a Stokes number as practical in this setting was sought, without incurring high initial pressure drops through the AER itself (a maximum allowable pressure drop of $50 \mathrm{~Pa}$ was included in the design).

The Stokes Number $(S t)$ is a dimensionless quantity corresponding to the behaviour of particles suspended in a fluid flow. It is the ratio of the characteristic response time of a particle to the 
characteristic response time of a fluid flow. Stokes number can be determined according to Equation 2 where $D$, is the equivalent aerodynamic diameter of the particles in question $(\mathrm{m}) ; U_{0}$ is the velocity of ambient air flow $(\mathrm{m} / \mathrm{s}) ; \delta$ is the diameter of the sampling tube $(\mathrm{m}) ; \lambda$ is the particle density $\left(\mathrm{kg} / \mathrm{m}^{3}\right)$; and $\mu$ is the viscosity of the fluid (Pa.s) [22].

$$
S t=\frac{D^{2} \lambda U_{0}}{18 \mu \delta}
$$

The original 1:4 scale AER prototype shown in Figure 1 used an air intake comprising of 58 no. $25 \mathrm{~mm}$ inlets. This scaled prototype was tested at ventilation rates of only $1,300 \mathrm{~m}^{3} / \mathrm{hr}$ to limit the velocity through the inlets to be $<1 \mathrm{~m} / \mathrm{s}$. At higher velocities, CFD simulations had shown the aspiration efficiency and energy consumption would increase [15]. To maintain the ventilation velocity to be $<1 \mathrm{~m} / \mathrm{s}$ in the full-scale AER-AHU an increase in cross-sectional area larger than the cross-sectional area of the 860 × $600 \mathrm{~mm}$ AHU was necessary. As shown in Figure 2 the AERAHU comprised 48 No. $160 \mathrm{~mm}$ inlets. The concept of using an array of sampling inlets in the original prototype was also maintained here in an attempt to maintain the known behaviour of PM air samplers, but moving to the larger scale setting of building ventilation. Figure 3 illustrates the design layout of the Control-AHU and AER- AHU, both fitted with F7 bag filters (MERV 13) and G4 panel filters (MERV 8). 
(a)

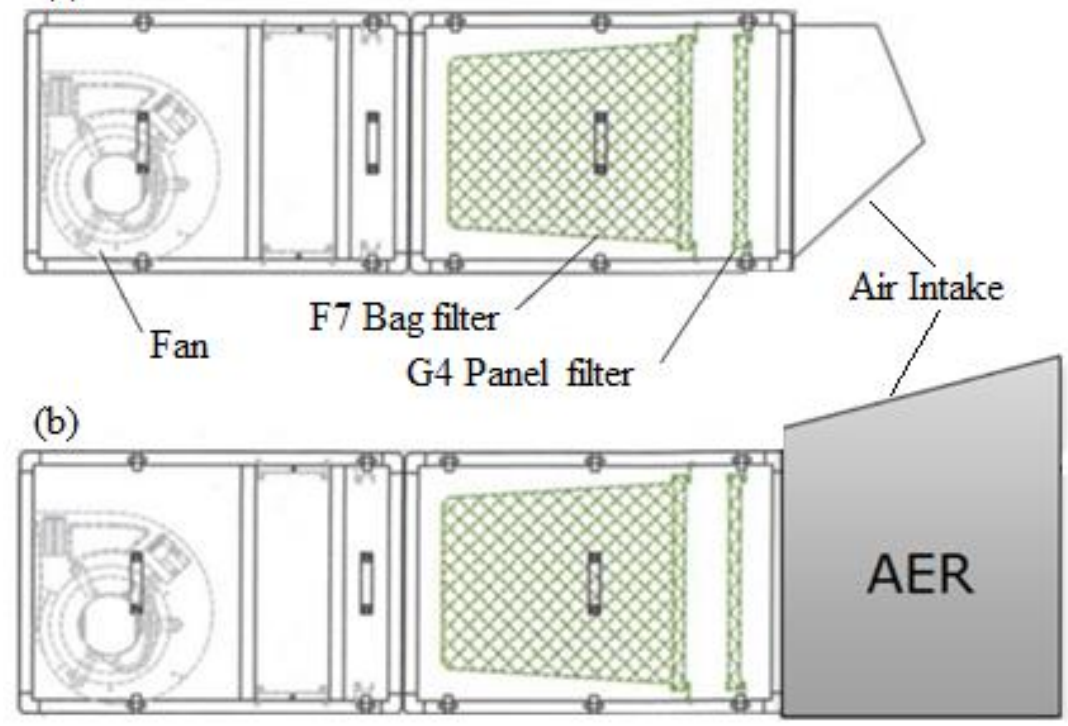

Figure 3. Cross-sectional view of a) Control-AHU, and b) full-scale AER-AHU.

\subsection{Installation and monitoring}

The two AHUs were both instrumented to monitor pressure drop across the filters, and PM concentrations inside and upstream of the AHUs (Figure 4). 


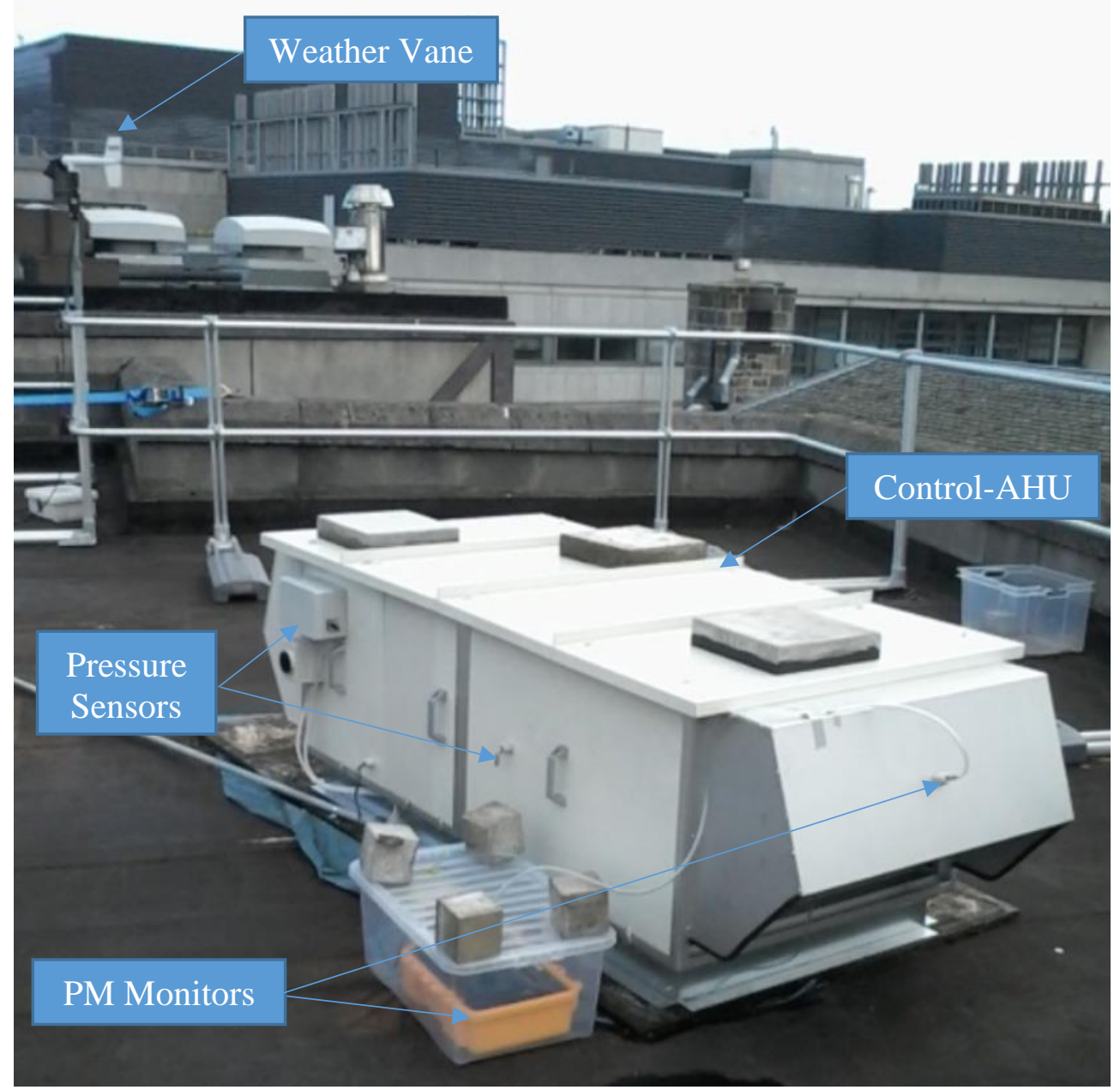

Figure 4. Instrumentation to record atmpshieric PM concentrations and local meteoroligical conditions at Control-AHU.

Wind speed and direction, important factors affecting aspiration efficiency, were monitored using a Campbell Scientific 05103 anemometer at 10-minute intervals. Air samplers measured PM concentrations in the atmosphere, entering the Control-AHU, and entering the AER-AHU. These were MetOne Aerocet 531 optical particle profilers, capable of measuring PM concentrations in the following ranges $<1,<2.5,<7,<10 \mu \mathrm{m}$ and total suspended particles (TSP), at 2-minute intervals. For Quality control purposes the optical measurements were also periodically verified with gravimetric measurements of PM using a Hazdust EPAM 5000 air sampler. Gravimetric analysis was conducted on these samples as described by [23]. Pressure sensors were used to 
measure pressure drop (and hence to calculate energy consumption) in the Control- and AERAHUs. Energy consumption was determined in each AHU according to Equation 3 [24].

$$
W=\frac{q_{V} \cdot \Delta p \cdot t}{1000 \cdot \eta}
$$

Where $W$ (in $\mathrm{kW}$ ) is the energy consumption of a fabric filter; $q_{v}$ is the ventilation flow rate $=3400$ $\mathrm{m}^{3} / \mathrm{h} ; \eta$ is the ventilation fans efficiency also taken as a fixed standard of $50 \% ; \Delta p$ is the pressure drop in $\mathrm{Pa}$; and $t$ is the time in hours.

\subsection{Particle size distribution}

In order to further validate the pollution control, energy and filter life impacts of the AER device, scanning electron microscopy (SEM) was used to examine the size distribution of particles passing through the AER-AHU in comparison to the Control-AHU. In theory aspiration efficiency is lower for larger particle sizes when wind direction is opposite to the sampling direction. Therefore the AER-AHU would be expected to prevent a greater proportion of coarse particles $\left(\mathrm{PM}_{10}-\mathrm{PM}_{50}\right)$ from reaching the HVAC filters than finer particles $\left(<\mathrm{PM}_{2.5}\right)$. As such it could be expected that more coarse material would be deposited on the filters in the Control-AHU in comparison to the AER-AHU.

A high resolution SEM Tescan Mira II XMU was used in this study to analyse particle distributions on a number of filter samples. Used panel filters from the completed AHU testing were examined. Six samples were collected from the trough and crest of the used panel filter material as a comparison between the filters for the AER-AHU and the Control-AHU. Small segments were cut 
out from the centre of the filters and labelled 'Control' and 'AER'. Each of the filters were also shaken separately over a piece of paper. The dust and particles on the paper, varying in sizes, were emptied into a petri dish to provide two additional samples.

Samples were attached to small aluminium stubs to be placed in the microscope. A thin film of double sided tape was placed over two of the stubs. These were dipped into each petri dish, with the top surface of the stubs becoming covered in particles. Four more stubs were then prepared for the cut filter segments. Carbon cement was spread across these four stubs. The four filter segments were then pressed down onto the stubs. Once the cement had dried, a thin layer of carbon coating applied to each sample. The list of filter samples that were analysed included two sample for each of the following:

i. Dust shaken from the filters

ii. The crest from a segment of the filters

iii. The trough from a segment of the filters.

Particle size distributions were then determined using microscopic images taken of the samples using the SEM in combination with Image J software, as described by Schneider et al [25]. 'Image $\mathrm{J}^{\prime}$ is an image analysis tool developed by the US National Institute of Health [25]. This program was used on the highest magnification image from each of the six samples. Based on the brightness of pixels in the image, the software distinguished between particles and background material. For the two dust samples the background material was the aluminium stub. For the trough and crest samples the background material was the filter fabric itself. An example is shown in Figure 5, where green regions have been identified as particles. The Feret diameter, particle area, and number of particles, were subsequently determined by the software. The distribution of particle sizes, 
average size and area were calculated for each sample. Comparisons could then be made between the characteristics of particles present on the Control and AER filters.

The rate of particle loss from the used HVAC filters during their operation, removal and processing was not accounted for here. As such the resulting particle size distributions give an approximate indication of the average distribution over the 3-month sampling period.
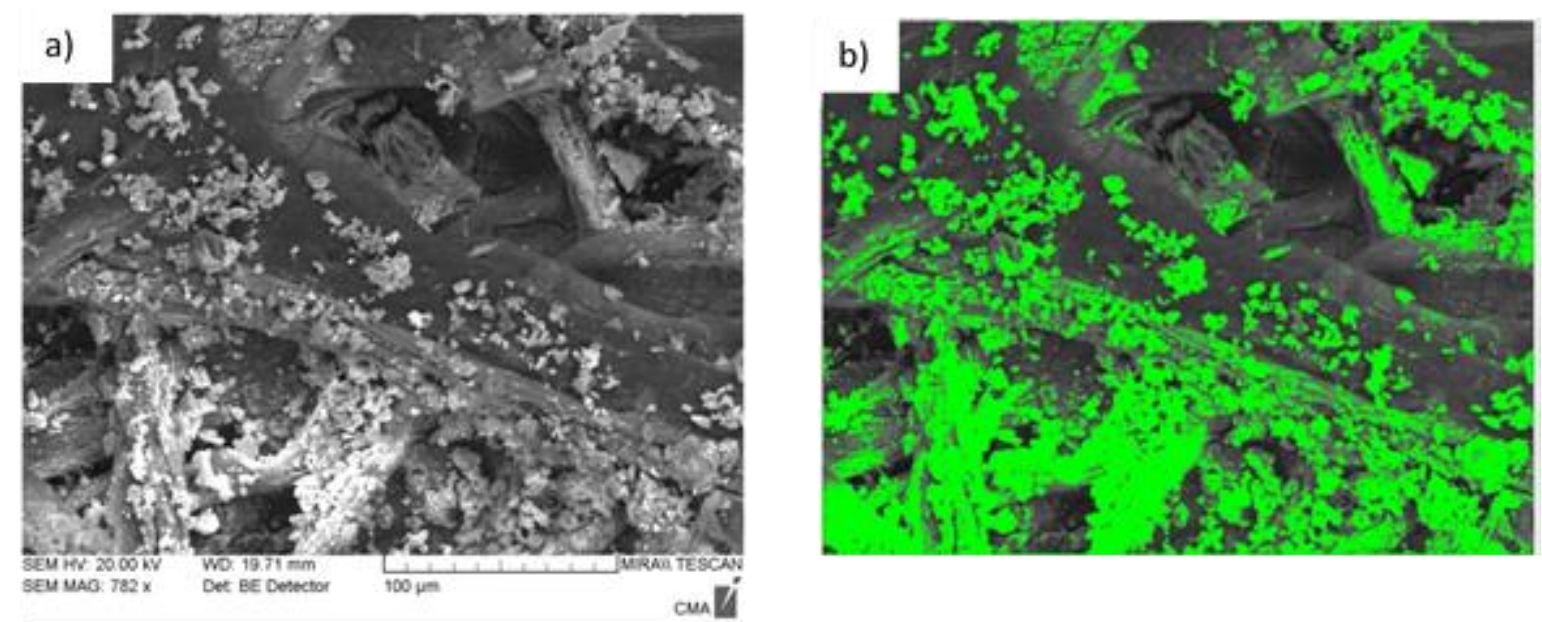

Figure 5. a) SEM micro image of particles on AER filter, crest sample; b) Image J analysis of deposited PM (green areas).

\section{Results}

\subsection{Long term performance assessment}

6 The performance of the AER-AHU in comparison to the Control-AHU is shown in Figure 6. The

7 initial pressure drop created by the AER inlet was measured at $30 \mathrm{~Pa}$, which was less than the initial

8 pressure drop created by the original rain hood fitted to the Control-AHU. The initial pressure drop

9 across the full scale AER-AHU was $236 \mathrm{~Pa}$ compared to $248 \mathrm{~Pa}$ in the Control-AHU. Both the rain

10 hood and AER were effective in preventing water droplets entering the AHUs. 


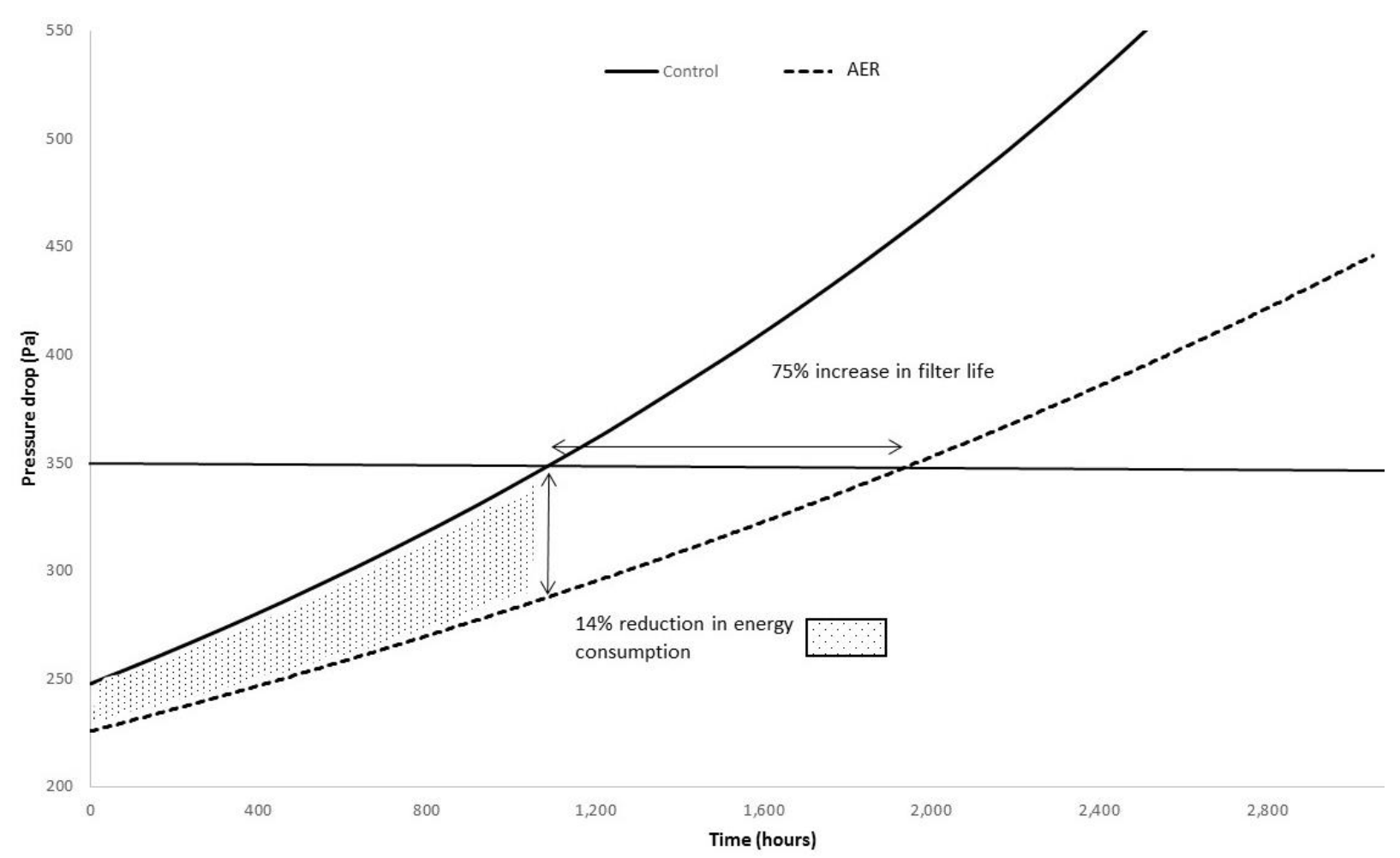

15 Monitoring took place over a 4-month period, comprising over 3,000 hours of AHU running time

23 Manufacturer specifications typically recommend that used filters are replaced in this setting, once

24 the pressure drop reaches $350 \mathrm{~Pa}$ (i.e. an addition of approximately $100 \mathrm{~Pa}$ above the initial system
Figure 6. Measured pressure drop in Control-AHU and AER-AHU over approximately 3,000 hours in operation (equivalent to 125 days running 24 hours per day). and monitoring data. The average ambient levels of $\mathrm{PM}_{10}$ and $\mathrm{PM}_{2.5}$ during the monitoring period were $18 \mu \mathrm{g} / \mathrm{m}^{3}$ and $7 \mu \mathrm{g} / \mathrm{m}^{3}$ respectively. From Figure it is apparent that increases in the ControlAHU and AER-AHU pressure drops occurred due to the cumulative loading of the filters with ambient airborne PM. Due to the lower rate of particle loading in the AER-AHU, the pressure drop increased in the HVAC system at a slower rate than in the Control-AHU, resulting in a $94.2 \mathrm{kWh}$ saving over the life of the filters. This translated to a $14 \%$ energy saving. pressure drop). This recommendation is typically adhered to where filters are changed every six 
26 months, as sensors to indicate pressure drop are often lacking or not regularly checked in

27 conventional commercial buildings. In this study $350 \mathrm{~Pa}$ was reached by the Control-AHU after

281,152 hours of testing. The AER-AHU reached the 350 Pa point after 2,016 hours, lasting $75 \%$

29 longer than the Control- AHU.

31 Assuming that an AHU in a commercial buildings is typically in operation 8-12 hours per day from

32 Monday to Friday, this results in a required filter change after approximately 4.5-6.6 months for

33 the Control-AHU and 7.8-11.6 months for the AER-AHU.

35 There is no strong regulation of filter changes in Ireland, or in many countries for that matter, and

36 filters are not always changed routinely. Therefore, for demonstration purposes, testing continued

37 beyond $350 \mathrm{~Pa}$ to investigate the performance of the filters beyond their recommended operational

38 lifespan and to determine how the AER performed in this case. If the filters were not changed as

39 recommended, the energy saving was deemed to be larger. Similarly for a building operating for

40 more than 12 hours per day, and five days per week, the energy saving would also be larger. The

41 results showed that by the time the AER-AHU reached $350 \mathrm{~Pa}$, the Control-AHU had consumed

$42260 \mathrm{kWh}$ or $24 \%$ more energy.

44 The accumulated mass of PM on the AER-AHU filters at the end of filter life was $71.2 \mathrm{~g}$, while $45108.3 \mathrm{~g}$ of particulates had accumulated on the Control-AHU filters during the same time period, 46 resulting in an average aspiration efficiency of the AER-AHU of $65 \%$. This was a poorer 47 performance that the original scaled prototype device which achieved a 54\% AE [15]. The increase 48 in AE is likely to have been as a result of increases in the diameter of the inlets ( $25 \mathrm{~mm}$ to $160 \mathrm{~mm}$ ) 49 and the inability of the AER-AHU to rotate to be always opposite in direction to the ambient wind. 
50 Ambient wind at the field test location was predominantly at $270^{\circ}$. Significant deviations from the

51 prevailing wind direction were uncommon during the sampling period.

53 The unexpected higher initial pressure drop from the rain hood in the Control-AHU could have the

54 effect of inflating the energy or filter life savings achievable in this comparison, as it may be

55 possible to re-design the original rain hood to have a lower pressure drop. In order to assess the

56 impact of this, an assessment was made assuming that the rain hood in the Control-AHU had the

57 same initial pressure drop as the AER. It was also assumed that the Control-AHU in this

58 hypothetical scenario followed the same pressure drop increase rate as shown in Figure 6, but

59 transposed downwards by the lower initial pressure drop. This resulted in the estimated energy

60 saving reducing from $14 \%$ to $11 \%$ and the estimated filter life extension was also reduced from

$6175 \%$ to $59 \%$.

\section{$63 \quad 4.2$ Economic viability}

64 The economic viability of the design was subsequently examined including: i) the energy; and ii)

65 the filter savings. After a five-year return period, it was estimated that the AER would save $€ 209-$

66260 in energy cost or $€ 160-214$ in extending filter lifespans. Energy and filter savings were

67 determined according to Table 1. For energy savings estimation, it was assumed that 2-2.5 filter

68 changes were conducted per annum (depending on whether the building HVAC system operates

69 for 8 or 12 hours/day). The mean commercial electricity unit cost in Ireland, including all related

70 taxes and charges was used as $€ 0.22 / \mathrm{kWh}$, and this was used as mean of financial return to building

71 owners.

72

73 Table 1. Energy and filter life cost estimation for AER. 


\begin{tabular}{lrrlr}
\hline \multicolumn{2}{c}{ Energy Savings } & & & \multicolumn{2}{c}{ Filter Savings } \\
\cline { 1 - 2 } Energy saving per filter & $94.2 \mathrm{kWh}$ & & Extension in filter life & $75 \%$ \\
Cost of 1 kWh & $€ 0.22$ & & Life cycle cost of filters* & $€ 75-100$ \\
Filter changes per annum & $2.0-2.5$ & & Reduction in cost per annum & $€ 56-75$ \\
5 year energy saving & $€ 209-260$ & & 5 year filter saving & $€ 160-214$ \\
\hline *includes installation \& replacement; assuming two pleated and one bag filter change per annum.
\end{tabular}

75 To estimate the cost saving of extending the filter life, a life cycle cost for two panel and one bag

76 filter replacement per year was estimated at $€ 75-100$. The price range was used to account for the

77 variation in the labour costs based on accessibility and location of some buildings. In the case of

78 the AER-AHU less than two panel and one bag filter replacements would be required each year

79 and hence material, labour and disposal cost savings would be achieved for the building owner.

81 The cost of manufacturing a commercial AER device was estimated at between $€ 200$ and $€ 250$,

82 which included the additional material and manufacturing costs for the device. The annual cost of

83 maintenance was considered negligible, as the cleaning of any particle build up in the base of the

84 device could be cleared in parallel with the replacement of filters and have no added cost to routine

85 maintenance. This suggests that the AER device would have the equivalent savings associated with

86 reduced energy or filter demands for the AHU device. However the cost of an AER device would

87 be considered less for a larger HVAC unit as the cost of scaling up the device would not be

88 proportional to the equivalent energy or filter savings. Furthermore, the economic savings of the

89 passive AER device on a continuous 24-hour AHU or larger HVAC unit would present a stronger

90 economic case as the device could at least double the savings in energy or filter demands.

91

924.3 Particle Size Distributions 
93 As shown in Section 4.1 the filters in the AER-AHU were loaded with significantly less PM than

94 the Control-AHU over the testing period, despite being co-located and subject to identical operating

95 conditions. Investigating this further, the size distribution of particles deposited on the filters allows

96 us to confirm the nature of the AER device whereby greater proportions of coarse particles were

97 expected to be prevented from reaching the filter material, compared to the control. Table 3 outlines

98 the number of particles, the average area of filter material that was covered with particles, and the

99 average particle Feret diameters. The average values in Table 3 were averages across SEM image

100 in each case, output by the ImageJ softwared. Additional SEM imagery is appended in Figures S1

101 to S3 of the supplementary materials section, showing typical views for each of the filter samples.

102 Figure 7 illustrates the distribution of particle numbers on the filters according to size

103 classifications in the Control-AHU and AER-AHU units.

104

105 Table 3. Comparison between the number of particles, average area, and average Feret diameter 106 of material deposited on the Control-AHU and AER-AHU panel filters.

\begin{tabular}{|c|c|c|c|c|c|}
\hline & \multirow[t]{2}{*}{ Sample } & $\begin{array}{c}\text { No. of particles } \\
\text { detected }\end{array}$ & Magnification* & $\begin{array}{l}\text { Average } \\
\text { area*** }^{*}\end{array}$ & $\begin{array}{c}\text { Average Feret } \\
\text { diameter }^{+}\end{array}$ \\
\hline & & Count & $\mathrm{X}$ & $\mu \mathrm{m}^{2}$ & $\mu \mathrm{m}$ \\
\hline \multirow{3}{*}{ Control } & Dust Sample & 2,895 & 312 & $\begin{array}{r}2.140 \\
(4.452)\end{array}$ & $\begin{array}{r}2.134 \\
(1.989)\end{array}$ \\
\hline & Crest & 981 & 868 & $\begin{array}{r}1.726 \\
(17.101)\end{array}$ & $\begin{array}{r}1.238 \\
(2.386)\end{array}$ \\
\hline & Trough & 1,350 & 859 & $\begin{array}{r}0.861 \\
(5.151) \\
\end{array}$ & $\begin{array}{r}1.028 \\
(1.798)\end{array}$ \\
\hline \multirow{3}{*}{ AER } & Dust Sample & 2,178 & 957 & $\begin{array}{r}0.487 \\
(2.578)\end{array}$ & $\begin{array}{r}0.807 \\
(1.228)\end{array}$ \\
\hline & Crest & 1,709 & 782 & $\begin{array}{r}1.470 \\
(25.506)\end{array}$ & $\begin{array}{r}1.142 \\
(2.359)\end{array}$ \\
\hline & Trough & 3,020 & 1,090 & $\begin{array}{r}0.866 \\
(10.141) \\
\end{array}$ & $\begin{array}{r}0.822 \\
(1.948) \\
\end{array}$ \\
\hline
\end{tabular}

$107 *$ SEM Image magnification

$108 * *$ Average areas of particles on HVAC filter samples and standard deviations in brackets

$109+$ Average ferret diameter (measure of an objects size along s specific direction i.e. perpendicular

110 to the SEM), and standard deviation in brackets. 

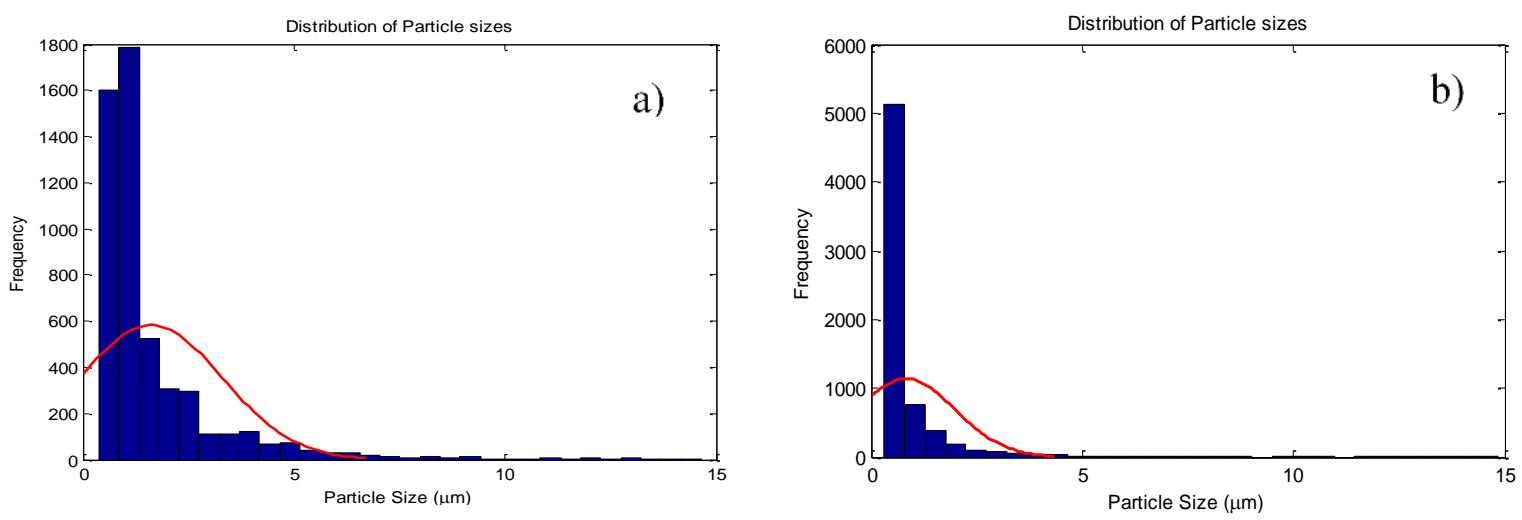

112

Figure 7. Particle size distributions for the a) Control-AHU filters, and b) AER-AHU filters.

As can be seen in Table 3 the PM deposited on the control filters were larger in diameter across all three sample types than those on the AER filters. The $0.86-1.33 \mu \mathrm{m}$ diameter bin contained the highest frequency of particle sizes in Control AHU. There were 1,788 occurrences of particles sized in this range. For the AER-AHU the $0.30-0.79 \mu \mathrm{m}$ bin contained the highest frequency of particle sizes with 5,136 known particles sized in this range. Overall the size of particles in the AER filters were noticeably smaller than the control, confirming the theory that the device is more effective at preventing intake of coarser particles. The AER filters also showed a noticeably larger number of particles than the control.

In total the particle size distribution across the 3 samples taken on the Control-AHU filter identified 5226 particles $($ mean size $=1.680 \mu \mathrm{m} ;$ St.Dev $=2.086 \mu \mathrm{m})$, while on the AER-AHU filter 6906 particles were recorded $($ mean size $=0.896 \mu \mathrm{m} ; \mathrm{St} . \mathrm{D}=1.879 \mu \mathrm{m})$. It could be expected that if the AER acted to prevent more of the larger size particles from reaching its filters that a similar number of smaller particles would be found in both the Control and AER. In Figure 7 significantly more smaller sized particles were found on the AER and this may be due to shortcomings of the SEM/image analysis where larger particles on the Control have obscured the smaller particles 
131 which may not have been identified. In addition a certain degree of natural variation between the

132 two could be expected in a field-based long term experiment. Regardless of this limitation the 133 overriding evidence of large particles on the Control-AHU filters remains valid.

135 It should be noted that while previous investigations have used a combination of SEM and ImageJ

136 analysis to determine particle size and distribution [26], HVAC filters are not intended for the

137 purpose of sample collection. The above results are limited to providing an approximation of the

138 particle size distribution on the surface of the HVAC filters only, over a 3 month period.

139 SEM/image analysis may fail to fully identify all particles due to larger particles obscuring smaller

140 partilces, or adjacent particles being incorrectly counted as one. More specific particle size

141 distribution experimentation is required to fully characterise the distribution of particles upstream 142 and downstream of the AER, in future studies.

\section{5. Discussion}

1455.1 Energy savings, filter life \& environmental impact

146 The results of this investigation highlight that relatively simple alterations to the intake of an AHU

147 can result in significant reductions in energy consumption by the fan or reduction in the need to 148 replace filters. Adapted to the many AHUs in existence around the world this technology could 149 achieve a significant positive impact on the environment and reduce the current detriment caused 150 by the control of indoor air pollution in buildings.

152 At full scale the AER retained much of the performance of the original scale model despite large 153 increases in its physical size, increases in the diameter of the inlets, and a reduction in wind 154 direction component of the design. Having the inlet of an orifice to be always opposite in direction 
155 to the ambient wind was shown by previous investigators to result in reductions in AE [15, 19-21].

156 At full scale it was impractical to rotate the AER due to its size and weight. In addition the cost of

157 the incorporation of a rotation mechanism would likely outweigh or significantly reduce the

158 economic savings attained from energy performance or filter changes.

160 There was little deviation in the ambient wind direction from the prevailing direction during the

161 field assessment meaning that the fixed nature of the AER-AHU (fixed to be opposite to the 162 prevailing wind) was sufficient to achieve savings. Furthermore, it was also clear from the results 163 that a fully rotating AER would have only improved the energy saving performance marginally.

164 This was due to energy savings being achieved over a longer period of time, and the few occasions 165 where the ambient wind directions was significantly different to the prevailing direction, resulting 166 in higher AE values, did not impact on the overall result significantly. Perhaps in other locations 167 around the world, the prevailing wind may be less dominant than in Ireland, and the performance 168 of the device would not be at the same level.

170 A further limitation of the current design of the AER is its physical size. Maintaining the design 171 principle of providing a lower intake velocity $(1 \mathrm{~m} / \mathrm{s})$ requires a considerable increase in AHU 172 cross-sectional area, where the ventilation flow rate is maintained. Here, the AER-AHU increases 173 in cross-section by over three-fold, from $0.5 \mathrm{~m}^{2}$ to over $1.8 \mathrm{~m}^{2}$. While the current device is a full 174 scale demonstration, AHUs come in various sizes depending on the ventilation rate required. Flow 175 rates of up to $75,000 \mathrm{~m}^{3} / \mathrm{hr}$ are common in large industrial settings. Thus scaling the current AER176 AHU up further from the current AHU size would quickly result in an impractically large inlet 177 design. Further research is therefore required to reduce the physical size of the AER while retaining 178 its performance capabilities. This may include examining performance for marginally larger 
179 ventilation velocities, as the value of $1 \mathrm{~m} / \mathrm{s}$ as a design criterion has not been optimised in this or

180 previous investigations.

181

182 Indeed the optimisation of the AER requires further detailed laboratory or CFD based investigation.

183 In the design of the AER the interests of pollution control and energy saving performance are

184 sometimes competing i.e. certain actions to improve the pollution control capability may increase

185 the initial pressure drop of the device, negating or outweighing the energy saving. As such a balance

186 between the two must be struck. In the present study a balance has been achieved, resulting in 14\%

187 energy saving, but the design has not been optimised. Considering the length of time required to

188 conduct one full scale test on a set of filters (circa 3 months) this form of assessment would not be

189 suitable for the optimisation process. Controlled experimentation for all factors affecting AE and 190 pressure drop are required to find the optimal balance.

191

\subsection{Used filters \& replacements}

193 Notwithstanding the aforementioned limitations, the AERs ability to prolong filter life was also an

194 encouraging result from the field assessment results. The potential savings in cost to building

195 operators where shown to be very similar to the savings arising from reductions in energy cost.

196 Furthermore, filter changes in commercial buildings is not a strongly regulated area in many

197 countries and thus filters may often be left in place beyond their intended life span. This is a known

198 source of significant indoor air quality problems including sick building syndrome [6]. The AER

199 may therefore offer the potential to reduce the risk of dirty filters impacting on indoor air quality.

201 The results of the field campaign showed that the filters were used after 1,152 hours of operation.

202 Depending on how many hours a building operates its HVAC system this could mean filter changes 
203 required every 4.5-6.6 months (assuming 8-12 hours/day Monday to Friday). However for 24/7

204 operation as is the case in some buildings the filters used here would only last 6.8 weeks. In

205 addition, outdoor air quality in Dublin is generally quite good by international standards and hence

206 the amount of time the filters used here would last in larger more polluted cities would be less.

208 Therefore, the rule of thumb of requiring filter changes every six months may in certain 209 circumstances be considerably less than optimum and the installation of an AER in such instances 210 would alleviate this.

\subsection{Particle size distribution}

213 The SEM and imagine analysis conducted on size samples from the AER and Control filters further 214 validated the operation of the AER as an aspiration efficiency reducer. This HVAC inlet design

215 was subject to the many factors which influence the magnitude of AE: ambient wind speed and 216 direction, ventilation rate, and particle size. Where particle sizes are larger than $\mathrm{PM}_{2.5}$, the AER

217 has been shown to perform more effectively as a passive control mechanism. This has been shown

218 to be the case here whereby in two co-located AHUs the AER-AHU prevented a larger amount of 219 coarse particles from reaching its filter media compared to the Control. However the limitations 220 noted in Section 4.3 require that more detailed particle size distribution analysis is required in

221 laboratory controlled conditions to fully characterise the impacts of the AER on differing sizes of 222 particles. SEM and ImageJ analysis on used HVAC filters only provides an approximate 223 assessment of the particle size distribution over the 3 month testing period.

\subsection{Aspiration efficiency concept in pollution control}


226 PM concentrations passing through an orifice have been shown by this and many previous

227 investigations to have the potential to differ significantly from ambient concentration. The average

$228 \mathrm{AE}$ here was $65 \%$ and values quoted in the literature for ventilation systems, air samplers and the

229 human nose/mouth vary widely depending on environmental and particle factors. This study has

230 also demonstrated that the AE concept can be incorporated into air pollution control systems with

231 significant results. The capability of an AE based control is not on the same level of performance

232 as fabric filtration e.g. at $\mathrm{PM}_{0.4}$ the effects of $\mathrm{AE}$ may be very small while filters can retain

233 significant effectiveness. Few previous investigations have examined the impacts of AE on the

234 ultrafine size fraction and this was also not included in the present study. As such there exists a gap

235 in knowledge as to the behaviour of ultrafine particles in the context of AE here. However, as a

236 form of pre-filter this passive method has shown good potential to improve the sustainability of 237 indoor air pollution control.

239 The AE concept may also have application in other environments such as vehicular cabins or in 240 particle separation processes. Both require further research.

\subsection{Insight to financial benefit of the AER on the HVAC sector}

243 Assuming that the 2007 estimations for electricity consumed by HVAC systems in Europe has

244 remained similar over the past decade [10], then achieving half of the 14\% energy savings from

245 the cost of this $313 \mathrm{TWh}$ equates to approximately $€ 500$ million per year (using $€ 0.22$ per $\mathrm{kWh}$

246 from Section 4.2). Further analysis is required to determine how the AER would perform in 247 different climatic and pollution conditions around the globe. 


\section{Conclusions}

251 In conclusion the full-scale static frame AER device was shown to have the ability to: i) reduce

252 AHU energy consumption by $14 \%$; or ii) increase filter life by $75 \%$. In addition the physical size

253 of the current AER-AHU design is its current limitation as it prevents its extrapolation to larger

254 AHUs.

255

256 However the concept of using aspiration efficiency as a passive method to control air pollution has

257 shown significant potential to improve the environmental impact of indoor air pollution control in

258 buildings. Extrapolation of this technology to the numerous AHUs in existence would have

259 significant positive impacts on the environment.

\section{Acknowledgements}

264 The authors would like to acknowledge the part funding of this project by: Enterprise Ireland, 265 Innovation Partnership Programme (EI-IP.2013.0279); European Regional Development Fund (EI-

266 IP.2013.0279); and Mark Eire BV (EI-IP.2013.0279). The funding agencies had no role in the 267 design of the study; collection, analysis or interpretation of data; writing of this paper; or the 268 decision to submit it for publication.

\section{References}

271 [1] Kan H, Chen R, Tong S. Ambient air pollution, climate change, and population health in China. 272 Environment International. 2012;42:10-9.

273 [2] Pérez-Lombard L, Ortiz J, Pout C. A review on buildings energy consumption information. 274 Energy and Buildings. 2008;40:394-8. 
[3] Azimi P, Zhao D, Stephens B. Estimates of HVAC filtration efficiency for fine and ultrafine particles of outdoor origin. Atmospheric Environment. 2014;98:337-46.

[4] Waring MS, Siegel JA. Particle loading rates for HVAC filters, heat exchangers, and ducts. Indoor Air. 2008;18:209-24.

[5] Bekö G, Fadeyi MO, Clausen G, Weschler CJ. Sensory pollution from bag-type fiberglass ventilation filters: Conventional filter compared with filters containing various amounts of activated carbon. Building and Environment. 2009;44:2114-20.

[6] Fisk WJ. Health benefits of particle filtration. Indoor Air. 2013;23:357-68.

[7] Zaatari M, Siegel J. Particle characterization in retail environments: concentrations, sources, and removal mechanisms. Indoor Air. 2014;24:350-61.

[8] Vakiloroaya V, Samali B, Fakhar A, Pishghadam K. A review of different strategies for HVAC energy saving. Energy Conversion and Management. 2014;77:738-54.

[9] Perez-Lombard L, Ortiz J, Maestre IR. The map of energy flow in HVAC systems. Applied Energy. 2011;88:5020-31.

[10] Knight I. Assessing Electrical Energy Use In HVAC Systems. The REHVA European HVAC Journal. 2012:6-11.

[11] Cho J, Shin S, Kim J, Hong H. Development of an energy evaluation methodology to make multiple predictions of the HVAC\&amp;R system energy demand for office buildings. Energy and Buildings. 2014;80:169-83.

[12] Santos HRR, Leal VMS. Energy vs. ventilation rate in buildings: A comprehensive scenariobased assessment in the European context. Energy and Buildings. 2012;54:111-21.

[13] Rasouli M, Ge G, Simonson CJ, Besant RW. Uncertainties in energy and economic performance of HVAC systems and energy recovery ventilators due to uncertainties in building and HVAC parameters. Applied Thermal Engineering. 2013;50:732-42.

[14] Bhaskoro PT, Gilani SIUH, Aris MS. Simulation of energy saving potential of a centralized HVAC system in an academic building using adaptive cooling technique. Energy Conversion and Management. 2013;75:617-28.

[15] McNabola A, O'Luanaigh N, Gallagher J, Gill LW. The development and assessment of an aspiration efficiency reducing system of air pollution control for particulate matter in building ventilation systems. Energy and Buildings. 2013;61:177-84.

[16] Koehler KA, Anthony TR, Van Dyke M, Volckens J. Solid versus Liquid Particle Sampling Efficiency of Three Personal Aerosol Samplers when Facing the Wind. Annals of Occupational Hygiene. 2012;56:194-206.

[17] Kenny LC, R A, C C, Fabriès JF, Gonzalez-Fernandez E, Kromhout H, et al. A Collaborative European Study of Personal Inhalable Aerosol Sampler Performance. Annals of Occupational Hygiene. 1997;41:135-53.

[18] Lee EG, Lee T, Kim SW, Lee L, Flemmer MM, Harper M. Evaluation of pump pulsation in respirable size-selective sampling: part II. Changes in sampling efficiency. Ann Occup Hyg. 2014;58:74-84.

[19] McNabola A, Broderick B, Gill LW. A numerical analysis of the aspiration efficiency of a personal sampler. International Journal of Environment and Pollution 2010. 2010;41:pp. 109-23.

[20] Armbruster L, Breuer H. Investigations into defining inhalable dust. Annals of Occupational Hygiene. 1982;26:21-32.

[21] Wen X, Ingham DB. Aspiration efficiency of a thin-walled cylindrical aerosol sampler at yaw orientations with respect to the wind. Journal of Aerosol Science. 2000;31:1355-65.

[22] Dunnett SJ. A numerical study of the aspiration efficiency of a thin-walled sampler facing the wind for high velocity ratios. Journal of Aerosol Science. 2005;36:111-22. 
322 [23] McNabola A, Broderick BM, Gill LW. Relative exposure to fine particulate matter and VOCs 323 between transport microenvironments in Dublin: Personal exposure and uptake. Atmospheric 324 Environment. 2008;42:6496-512.

325 [24] Eurovent. Energy efficiency classification of air filters for general ventilation purposes. Paris, 326 France2014.

327 [25]. Schneider CA, Rasband WS, Eliceiri KW. NIH Image to ImageJ: 25 years of image analysis. 328 Nature Methods 2012; 9, 671-675.

329 [26]. Mazzoli A \& Favoni O (2012). Particle size, size distribution and morphological evaluation 330 of airborne dust particles of diverse woods by Scanning Electron Microscopy and image processing 331 programme. Powder Technology 225, 65-71. 